\title{
$\widehat{A}$ Madridge \\ madridge Journal of Nursing
}

Interconnecting Scientific World

Research Article

Open Access

\section{Is a Flipped Classroom an Effective Educational Method to meet Nursing Students Learning needs?}

\author{
Jessica Naber*, and Daniel Best \\ Department of Nursing, School of Nursing and Health Professions, Murray State University, Murray, USA
}

\section{Article Info}

*Corresponding author:
Jessica Naber
Assistant Professor
Department of Nursing
School of Nursing and Health Professions
Murray State University
Murray, USA
Tel. 502-541-3011
E-mail: jnaber@murraystate.edu

Received: January 30, 2016

Accepted: April 26, 2016

Published: April 28, 2016

Citation: Naber JL, Best DK. Is a flipped Classroom an effective Educational Method to meet Nursing Students Learning needs? Madridge J Nurs. 2016; 1(1): 7-10.

doi: 10.18689/mjn-1000102

Copyright: ( 2016 The Author(s). This work is licensed under a Creative Commons Attribution 4.0 International License, which permits unrestricted use, distribution, and reproduction in any medium, provided the original work is properly cited.

Published by Madridge Publishers

\begin{abstract}
Background: Due to the constantly changing environment in healthcare, nurses must be able to adjust their techniques, mind-set, and strategies to provide excellent care for their patients. Nurses are required to have the necessary skills to assess critically ill patients, provide emergent care, and identify subtle changes in health status; therefore, nurse educators must possess knowledge on current evidence-based methods that improve critical thinking and utilize active learning. The flipped classroom is a strategy that has been introduced in nursing education; however there is a shortage of empirical research regarding flipped classrooms and a lack of information and congruency about this educational strategy.
\end{abstract}

Methods: The authors investigated the effectiveness, benefits, and limitations involved with the implementation of the flipped classroom through previous studies and articles. Additionally, they distributed a questionnaire to students and faculty members to determine their opinions about the flipped classroom technique.

Results: Many benefits and limitations of flipped classrooms were identified through this study.

Conclusion: This information will be valuable for nursing educators in determining if they want to implement flipped classrooms, how to best define a flipped classroom, how to incorporate the strategy, and what obstacles to be aware of.

Keywords: Educational method; Flipped classroom; Nursing students; Educational strategy.

\section{Introduction}

In recent years there has been a desire for educational reform that can better educate students of this era, ranging from primary school to doctoral programs. The goal is for students to truly learn material and this is extremely crucial in healthcare. The Institute of Medicine (IOM) [1] report, Crossing the Quality Chasm, described the current healthcare workforce as inadequately prepared to meet the needs of a growing and increasingly diverse patient population. This report mentioned the fundamental competencies that all healthcare members should possess, these range from the ability to translate evidence into practice to proficient utilization of technological innovations to improve patient care. Traditional educational approaches can be a challenge to meet the previously stated requirements. Individuals in a healthcare setting must be able to critically think, defined by experts Paul and Scriven [2] as "actively and skillfully conceptualizing, applying, analyzing, synthesizing, and/or evaluating information gathered from, or generated by, observation, experience, reflection, reasoning, or 
communication". Nurse educators are challenged to find unique methods to assist students in applying, analyzing, and synthesizing information. The "flipped classroom" is a teaching strategy that has gained popularity in classrooms worldwide over the past decade. This paper will discuss the benefits and limitations of this educational strategy, results found from a survey of students and faculty, as well as recommendations for further research into the effectiveness of this technique.

\section{Background and Significance}

The term "flipped classroom" was coined in 2007 by two high school chemistry teachers in Colorado, Jonathon Bergmann and Aaron Sams [3]. They described the flipped classroom as follows: "that which is traditionally done in class is now done at home, and that which is traditionally done as homework is now completed in class" [3]. An example of a nursing flipped classroom would be where students in a Medical Surgical class were expected to watch a short film and view a lecture covering the material at home and during class would be expected to be able to "engage in class in active learning using case studies, labs, games, simulations, or experiments" [4].

Demski [5] mentioned that Harvard professor Eric Mazur, believe the flipped classroom is active learning at its best. Active learning is generally defined as an instructional method that engages students in learning. It requires students to do meaningful learning activities and think about what they are doing [6]. Demski [5] stated "That's how we all learn: by actively engaging in the material rather than sitting in a classroom and writing down the words said by a professor". Flipping a classroom makes the students actively participate in their own education, taking responsibility for their own learning [7].

\section{Implementation Strategies}

Explanation: A concern with the flipped classroom is that there are several methods of implementation. According to Hawks [7], one crucial point for implementation is explanation. Herreid and Schiller [4] stated that, "Students new to this method may be initially resistant because it requires that they do work at home". Faculty need to be very clear as to what they expect from the students for the semester. Faculty should spend the very first day with their students explaining the flipped classroom and expectations. They may even begin with a $Q \&$ A session for a few class meetings to alleviate any concerns. To promote student involvement, studies can be presented to validate the effectiveness of flipping a classroom. For example, Missildine, Fountain, Summers, and Gosselin [8] performed a study to determine the effects of a flipped classroom. A quasi-experimental design was used to compare traditional lecture to the flipped classroom approach. After flipping the classroom for a semester, "average examination scores were significantly higher" [8].

\section{Pre-Class Strategies}

The most basic form of flipping a classroom is to have students either read a specific chapter or view an online lecture covering certain material, and then the class time could be better used for active learning instead of lecturing. Some professors feel that the routine should involve students reading a chapter, taking notes over an online lecture, watching videos, and taking a pre-quiz before class begins [7]. Educators should assess students' understanding of the material before class with a pre-class quiz or some type of discussion board where questions can be asked for clarification. This way if class understanding has not occurred then more detail can be presented by the professor.

In the traditional classroom, educators are concerned about students coming to class unprepared for learning. The social pressure of the flipped classroom, working with other students in class on group projects, presentations, case studies, and activities, may force students to be prepared so the students do not disappoint group members.

\section{Answering Questions}

Answering student questions about content is highly important to student satisfaction and success. According to Pearson [9], some professors have online office hours specifically devoted to answering questions during pre-class homework time. By allowing students to contact them at a specific time every night online, they have made the opportunity for asking questions more personable and private. Additionally, a discussion board format can be used to ask questions prior to class, and faculty can respond before or during class.

\section{In-Class Strategies}

"The primary goals of this educational model are to enhance the relevance and retention of knowledge through rich interactive exercises and to facilitate in-depth learning fueled by individual students' aptitude and passion" [7]. During class time, active learning strategies are the priority. Case studies can be an effective tool used to assess the knowledge of the students in class with immediate feedback. From there the Nurse educator can adjust the schedule for the day to better educate the class on areas the students are struggling in. Another technique that can be used to educate students is an educational game. For example, if the topic is wound care, students could be asked to design a wound dressing out of classroom items and then present the dressing as an infomercial in one minute or less. Students are able to ask questions during the activity rather than having to wait until the end of class or interrupting lecture. With this type of activity, the unique thought process that occurs helps students to remember the material. The activities that can be done in class are limitless; there are online resources, and many faculty members rely on their own creativity to develop strategies. 


\section{Technology}

Demski [5] also suggested ideas and techniques to get this educational style implemented effectively. He stated that the use of existing technology is important so that students and teachers already understand software and programs they will be using. This technology is what the educator and students will be using outside of class for pre-class quizzes, recordings, videos, and other assignments. It can also be used for some in-class activities. It is important that both the educator and students are familiar with the software. If necessary, students can teach each other about the technology needed, which would then become another facet of active learning.

Many educators currently use Khan Academy videos which offer practice exercises, instruction, and a personalized learning dashboard that empower learners to study at their own pace in and outside of the classroom [10]. Other educators choose to make their own videos [9], and those can be stored on YouTube or archived on websites for other educators to use. The International Association of K-12 Online Education (iNACOL) said that the biggest mistake educators make with a flipped or online classroom is simply transferring what they do in a face-to-face setting [11]. If a nursing educator decides to make a video, it needs to be creative and engaging so students can focus on the important material and truly learn the core information. Anytime technology is implemented there is a potential for issues to arise to make its effectiveness reduced. Students may not have internet capability or they may have technical difficulties, but typically schools have computer labs, help desks, and other solutions to this dilemma.

Herreid and Schiller [4] said, "The bottom line is that we need more excellent cases supported by videos that are targeted, readily obtained/accessible (e.g., via YouTube), and need we say it again... free". There are online banks that have videos and case studies, but it can cost a lot of money to access or subscribe. More free educator-run sites for videos would be ideal.

\section{Rate of Implementation}

Another recommendation for faculty new to the technique is flipping the class in parts. The educator should start small, maybe only flipping the classes over topics students have historically comprehended well. From there, the educator can further implement this new strategy based off of feedback from the class and based on student results. Nursing programs may need to consider only flipping certain classes at certain levels rather than every class at every level all at once.

\section{Time Involved}

A main concern when discussing flipped classrooms is time. Nursing students are commonly expected to read multiple chapters prior to class which requires a considerable amount of time. When adding more pre-class work, such as videos, discussion boards, or quizzes this amount may overwhelm and frustrate students. In the previously mentioned study by Missildine, et al. [8], although exam averages increased with the flipped classroom, student satisfaction decreased due to the time involved in preparation. Likewise, professors will spend a large amount of time preparing for each class. The preparation consists of finding or creating prelecture videos that correctly correspond with each section as well as creating in class assignments like quizzes, group projects, and case studies.

\section{Recent Studies}

A descriptive study, aimed at understanding the opinions from students in a flipped classroom as well as professors who have already implemented this technique, was recently performed by the authors at a mid-size regional university. This study was approved by the university's IRB (Institutional Review Board), and both students' and professors' identities were kept confidential and anonymous. Students were asked to complete a questionnaire and return it. The students surveyed were first semester seniors who were currently in a course that, according to the professor, had been "flipped." Many of the open-ended responses revealed uncertainty on whether or not the technique was beneficial towards mastering in-class exams and for preparing for the NCLEX. Many participants stated they felt they were "teaching themselves" and they did not feel like they had a source to contact if confused while reading the assigned work before class. Other students were very positive, stating that they had more time to direct their own education and could "skip" areas they already felt comfortable in. Most of the written comments reflected negative views of the flipped classroom, but it is important to note that the surveys were submitted before midterm and could have changed with the progression of the semester and the adaptation of the students to this new technique. In addition, it is a limitation of this study that the opinions of these students were based mainly off of their experiences with one instructor and the techniques the instructor chose to utilize.

Three professors who have already implemented the flipped classroom approach were also asked to anonymously fill out a separate questionnaire made specifically for professors. All professors indicated that, in previous semesters, by the end of the semester their students had a positive experience with this new technique. All of the professors did state that there was an increase to their personal workload, with one professor stating that it "required more preparation for each class (case studies, discussion topics, and development)". An instructor also responded that flipped classrooms are "only as effective as any other assignment provided by instructors. There must be clear guidelines, direction, and motivation". All three professors stated that they will continue to use this technique and all would encourage other professors to utilize this as well. One professor stated that faculty members must "examine the feasibility of using this technique. It does not work for every classroom". 
In another recent study, "Flipped classroom trends: A survey of college faculty" [12], 1,089 faculty participants completed a survey about their flipped classroom experience. The researchers found that $70.3 \%$ of faculty found the experience to be positive for themselves, and $64.8 \%$ found it to be positive for their students. The most frequently stated reason the participants flipped their classrooms was because of a desire to increase student engagement, and $74.9 \%$ of educators noticed this occurring. Almost half of participants (54.66\%) saw improved student learning, but $48.75 \%$ noticed student resistance.

\section{Discussion}

The major concerns of students in the recent studies were time and the lack of help from their instructor while initially learning new material. These issues have been noted previously by Pearson [9]: "Students are not ready for a leap into a whole class of self-directed time. They [don't] know how to do that". Other students were concerned with effectiveness of this technique in preparing them for future exams. Herreid and Schiller [4] stated "students new to this method may be initially resistant", half of the participants in the study by Faculty Focus [12] mentioned that student resistance was noted, and Hawks [7] stated that early on in her implementation there was a lot of students resistance with this new technique. However, after they were used to it, many of them embraced it, and faculty in the authors' study mentioned that in previous semesters, students didn't feel the flipped classroom was helpful until the semester was over. Student involvement is paramount for the flipped classroom to succeed, but it may take time, experience, and positive results for students to be comfortable and in favor of the technique.

While there have not been very many studies done on this concept, the data corresponding with exam scores seem to represent a positive result. This was seen in several reports $[7,8,12]$. Also, Hawks [7] documented that fundamental competencies required of all healthcare professionals were identified in flipped classroom activities and outcomes:"the ability to translate evidence into practice; proficient utilization of technological innovations to improve patient care; membership in and collaboration on multidisciplinary teams; and recognition of complex care delivery arrangements and changing patient-clinician relationships" [7].

\section{Recommendations for Further Studies}

There is a lack of existing empirical work describing the effectiveness of the flipped classroom. Studies need to be performed in multiple university settings, particularly in nursing or healthcare related programs, to better understand the implications of flipping a classroom. To support the use of the flipped classroom, empirical evidence involving positive class, NCLEX, and practice outcomes would be beneficial. These studies need to incorporate professor and student, patient, and facility satisfaction and success, and need to be both cross-sectional and longitudinal. Additionally, specific activities, plans, and techniques need to be further explored so that guidelines for effective strategies could be available for use by educators. This could eliminate some of the time involved in preparation for faculty.

\section{Conclusion}

According to Hawks [7], the flipped classroom helps students "grow into becoming responsible, self-regulating learners". Evidence suggests that the flipped classroom is an active learning strategy that can improve critical thinking skills. The healthcare field, specifically nursing, needs to consider broader implementation of this style of education. Goodwin and Miller [13] stated "if we only implemented strategies supported by decades of research, we'd never try anything new". It is time alter current nursing educational tactics to better educate future healthcare workers and create a smarter and safer environment.

Conflicts of Interest: The author(s) report(s) no conflicts of interest.

Consent: No consent is required to our article publication.

\section{References}

1. Institute of Medicine. Crossing the quality chasm: A new health system for the 21st century. Washington, DC: National Academies Press; 2001.

2. Paul $R$, Scriven M. Defining critical thinking. Website http://www. criticalthinking.org/pages/defining-critical-thinking/766. Accessed April 27, 2016

3. Bergmann J, Sams A. Flip your classroom: Reach every student in every class every day. Eugene, OR: International Society for Technology in Education.

4. Herreid CF, Schiller NA. Case study: Case studies and the flipped classroom. Journal of College Science Teaching. 2014; 42(5): 62-67.

5. Demski J. 6 expert tips for flipping the classroom. Campus Technology. 2013; 25(5): 32-37.

6. Prince M. Does active learning work? A review of the research. Journal of Engineering Education. 2004; 93(3): 223-231. doi: 10.1002/j.2168-9830.2004.tb00809.x

7. Hawks SJ. The flipped classroom: Now or never? AANA Journal. 2014; 82(4): 264-269.

8. Missildine K, Fountain R, Summers L, Gosselin K. Flipping the classroom to improve student performance and satisfaction. J Nurs Educ. 2013; 52(10): 597-599. doi: 10.3928/01484834-20130919-03

9. Pearson G. Biology teacher's flipped classroom: "A simple thing, but it's so powerful". Education Canada. 2012; 52: 1-13.

10. Khan Academy. Our mission. Website https://www.khanacademy.org/. Accessed April 27, 2016.

11. Schachter R. Avoiding the pitfalls of virtual schooling. District Administration. 2012; 48(6): 74-76.

12. Faculty Focus. Flipped classroom trends: A survey of college faculty. Website http://www.facultyfocus.com/free-reports/flipped-classroo m-trends-a-survey-of-college-faculty/. Accessed April 27, 2016.

13. Goodwin B, Miller K. Evidence on flipped classrooms is still coming in. Educational Leadership. 2013; 70(6): 78-80. 